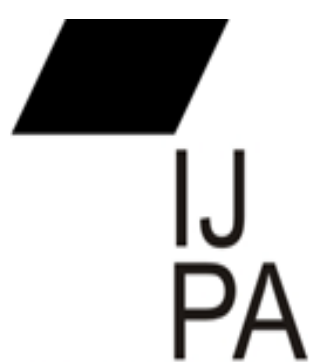

ISSN $2460=0369$

\section{IMPLEMENTASI LAYANAN PUBLIK TRANSJAKARTA CARES DALAM MENINGKATKAN AKSESIBILITAS PENYANDANG DISABILITAS DI WILAYAH PROVINSI DKI JAKARTA}

\author{
Evi Irviani, Hendra Wijayanto \\ Mahasiswi Prodi Administrasi Publik \\ Universitas 17 Agustus 1945 Jakarta \\ evi.irviani@gmail.com
}

\begin{abstract}
This study aims to determine the implementation of the Transjakarta Cares public service in increasing the accessibility of persons with disabilities in the DKI Jakarta area. This research uses qualitative research. The results of this study indicate that the implementation of the Transjakarta Cares public service in increasing the accessibility of persons is carried out. As seen in the standard and objective indicators, organizational characteristics, resources, social and economic conditions, attitudes of the implementers and organizational communications that support the implementation of the Transjakarta Cares service. The implementation of the Transjakarta Cares service is supported by good coordination, public support from both the government, the private sector and people with disabilities as service users. In addition, the implementation of this service is also supported by skilled and skilled human resources in providing services. However, the implementation of this service also faces obstacles, namely inadequate facility resources, namely the service car unit.
\end{abstract}

Keywords: Public Service, Transjakarta Cares, Policy Implementation

Abstrak, Penelitian ini bertujuan untuk mengetahui implementasi dari layanan publik Transjakarta Cares dalam meningkatkan aksesibilitas penyandang disabilitas di wilayah DKI Jakarta. Penelitian ini menggunakan jenis penelitian kualitatif. Hasil penelitian ini menunjukan bahwa implementasi layanan publik Transjakarta Cares dalam meningkatkan aksesibilitas penyandang dilaksanakan. Sebagaimana terlihat pada indiaktor standar dan tujuan, karakteristik organisasi, sumber daya, kondisi sosial dan ekonomi, sikap para pelaksana serta komunikasi organisasi yang mendukung pelaksanaan implementasi layanan Transjakarta Cares tersebut. Pelaksanaan layanan Transjakarta Cares ini didukung oleh koordinasi yang baik, dukungan publik baik dari pemerinytah, swasta maupun penyandang disabilitas sebagai pengguna layanan. Selain itu pelaksanaan layanan ini juga didukung oleh sumber daya manusia yang terampil dan cekatan dalam memberikan pelayanan. Namun, pegimplementasian layanan ini juga mendapatkan hambatan yakni kurang memadainya sumber daya fasilitas yakni unit mobil pelayanan.

Kata Kunci: Layanan Publik, Transjakarta Cares, Implementasi Kebijakan 


\section{PENDAHULUAN}

Transportasi merupakan bagian penting dalam kehidupan, sistem kemasyarakatan. Kondisi sosial demografis wilayah memiliki pengaruh terhadap kinerja transportasi di wilayah DKI Jakarta. Tuntutan perbaikan pelayanan publik dalam hal transportasi bagi masyarakat perkotaan sangat tinggi, hal tersebut karena peran transportasi sangat penting dalam peningkatan perekonomian suatu daerah.. Pemerintah selaku penyedia pelayanan publik dituntut untuk memenuhi kebutuhan transportasi bagi semua warga neagararnya tanpa terkecuali para penyandang disabilitas, yang merupakan kelompok minoritas dan hak-haknya sering terlewatkan Pemerintah. berperan penting dalam kehidupan penyandang disabilitas, dimana mereka membutuhkan perlakuan khusus untuk memperoleh layanan umum seperti pendidikan kesehatan, pekerjaan dan juga transportasi umum.

Regulasi pertama kali yang mengatur mengenai penyandang disabilitas yaitu UU Nomor 4 tahun 1997 tentang Penyandang Cacat. Dalam undang- undang tersebut penyandang disabilitas dilabeli dengan seseorang yang "cacat" atau "tidak normal", hal tersebut pula yang menimbulkan kesan bahwa seorang penyandang disabilitas lebih banyak dianggap sebagai objek yang perlu belas kasian dari orang lain. Untuk menggantikan undang-undang tersebut, di keluarkan UU Nomor 8 Tahun 2016 tentang Penyandang Disabilitas yang didalamnya penyandang disabilitas diakui keberadaanya dan memiliki hak yang sama dengan warga Negara lainya.

Berdasarkan hasil survey Pusat Data dan Informasi Kesejahteraan bekerja sama dengan PT Surveyor Indonesia (Persero) pada tahun 2016 sebanyak 12,5\% dari jumlah penduduk Indonesia merupakan penyandang disabilitas (Kementerian Sosial Republik Indonesia, 2016). Sedangkan data dari Survey Penduduk (Badan Pusat Statistik, 2010) mencatat 8,76\% penduduk Indonesia mengalami kesulitan fungsional. Pendekatan tingkat kesulitan fungsional dijadikan sumber informasi jumlah penyandang disabilitas. 
Table 1.

Presentasi Populasi Penyandang Keterbatasan di Indonesia pada 2020

\begin{tabular}{|c|l|l|}
\hline Number & Jenis Disabilitas & Percentage \\
\hline 1 & Trouble seeing & $3,05 \%$ \\
\hline 2 & Hearing Difficulty & $1,58 \%$ \\
\hline 3 & Difficulty walking / climbing stairs & $1,62 \%$ \\
\hline 4 & $\begin{array}{l}\text { Difficulty Remembering / } \\
\text { Concentrating }\end{array}$ & $1,44 \%$ \\
\hline
\end{tabular}

Pada tahun 2015, LBH Jakarta melakukan penelitian dengan memberikan penilaian terhadap aksesibilitas dari faslitas publik di DKI Jakarta. Dalam studi yang dilakukan LBH Jakarta melakukan penilaian/pemeringkatan terhadap fasilitas publikdi bangunan gedung pemerintahan, non-pemerintahan dan juga terhadap moda transportasi Transjakarta dan transportasi publik Kereta Api Komuter Line. Indikator penilaian yang digunakan yaitu mengacu pada unsur-unsur yang terdapat pada Pasal 4 Keputusan Menteri Perhubungan Nomor 71 Tahun 1999 dimana didalamnya mengatur tentang standar aksesibilitas prasarana angkutan umum. Kesimpulan dari hasil studi yang dilakukan oleh LBH Jakarta di tahun 2015 tersebut menyatakan bahwa layanan publik secara umum di Provinsi DKI Jakarta masih kurang mendukung pergerakan bagi penyandang disabilitas.

Berdasarkan hasil studi penilaian aksesibilitas layanan Transjakarta bagi penyandang disabilitas, dari 12 halte yang dijadikan objek observasi, terdapat 4 halte (Dukuh Atas, Harmoni, Sarinah, Glodok) yang mendapatkan nilai indeks tertinggi 2.1 dan hanya masuk ke dalam kategori "Kurang Aksesibel". Sedangkan, 8 halte Transjakarta masuk ke dalam kateori "Tidak Aksesibel”. Sehingga dapat ditarik kesimpulan dari hasil studi tersebut bahwa masih banyak kekuarangan yang dimiliki 
layanan transportasi publik Transjakarta. Seluruh sarana dan prasaran dalam objek observasi tidak berhasil memenui kriteria aksesibel bagi penyandang disabilitas (LBH, 2015).

Pada tanggal 19 Oktober 2016, PT Transjakarta meluncurkan layanan terbaru yang fungsinya untuk memudahkan pergerakan bagi penyandang disabilitas dan lansia yakni Transjakarta Cares. Melalui Transjakarta Cares para lansia dan penyandang disabilitas dapat melakukan perjalanan ke beberapa tempat di DKI Jakarta dengan sistem antar jemput penumpang. Dimana layanan ini akan memastikan pengguna layanan akan aman dan dilayani mulai dari rumah hingga lokasi yang dituju. Guna mengetahui bagaiamana pelaksanaan layanan tersebut penulis bertujuan untuk melakukan penelitian dengan judul Implementasi Layanan Publik Transjakarta Cares dalam meningkatkan Aksesibilitas Penyandang Disabilitas.

\section{KAJIAN TEORITIS}

\section{Kebijakan Publik}

Secara sederhana dapat dikatakan bahwa kebijakan publik adalah setiap keputusan yang dibuat oleh Negara. Kebijakan publik adalah strategi untuk mengantar masyarakat pada masa transisi, untuk menuju masyarakat yang dicitacitakan. Begitu besarnya peran kebijakan publik bagi setiap Negara sehingga banyak para ilmuan yang mencoba menerjemahkan kebijakan publik itu sendiri. Definisi yang sudah sering kita kenal yakni dari Thomas R. Dye yang mendefinisikan kebijakan publik sebagai segala sesuatu yang dilakukan oleh pemerintah, mengapa mereka melakukanya, dan hasil yang membuat sebuah kehidupan bersama tampil berbeda. Sedangkan menurut Harold Laswell dan Abraham Kaplan dalam (Nugroho, 2014) mendefinisikan kebijakan publik sebagai suatu program yang diproyeksi dengan tujuan-tujuan tertentu, nilai-nilai tertentu, dan praktik-praktik tertentu ( $a$ projected program of goals, value, and practices).

\section{Implementasi Kebijakan}

Sebagaimana dikemukakan oleh Peter deLeon dan Linda deLeon dalam buku (Nugroho, 2014) pendekatan dalam implementasi kebijakan digolongkan menjadi tiga 
generasi. Pada generasi pertama ditahun 1970-an implementasi kebijakan dipahami sebagai masalah-masalah yang terjadi antara kebijakan publik dan proses eksekusinya. Generasi kedua, ditahun 1980-an mulai dikembangkan implementasi kebijakan yang bersifat top-down perpective. Pada saat yang sama Generasi ketiga pada tahun 1990-an, ilmuan sosial bernama Malcolm L.Goggin memeperkenalkan pemikiran baru bahwa keberhasilan sebuah kebijakan publik ditentukan oleh perilaku aktor implementasi kebijakan.

Dalam penelitian ini penulis menggunakan model implementasi kebijakan yang diperkenalkan oleh Donald Van Meter dan Carl Van Horn disebut dengan $A$ Model Of Policy Implementation (1975). Pada dasarnya proses implementasi adalah suatu penerapan kebijakan yang dilakukan secara terencana dengan tujuan meraih kinerja implementasi yang tinggi yang berlangsung dalam hubungan antar variable tertentu. Model ini mengungkapkan bahwa implementasi kebijakan berjalan secara linier dari keputusan politik, pelaksana, hingga kinerja kebijakan publik itu sendiri. Van Meter dan Van Horn menjelaskan bahwa kinerja kebijakan dipengaruhi oleh beberapa variabel yang saling berkesinambungan, variabel tersebut yaitu:

a. Standar dan tujuan dasar kebijakan

b. Sumber daya

c. Karakteristik organisasi pelaksana

d. Sikap para pelaksana

e. Komunikasi antar organisasi dan kegiatan-kegiatan pelaksanaan

f. Kondisi sosial, ekonomi, dan politik

\section{Aksesibilitas}

Konsep aksesibilitas merujuk pada "kemudahan" yang tidak hanya mengacu pada lingkungan fisik tetapi juga pada sikap dan perlakukan kepada masyarakat difabel. Persoalan aksesibilitas merupakan persoalan yang kritis karena difabel hanya dapat berpartisipasi secara efektif ketika tersedia akses yang memadai. Akses yang dimaksud bukan hanya sebagai akses fisik menuju sebuah bangunan atau fasilitas

16 Available online at website: http://journal.uta45jakarta.ac.id/index.php/admpublik/iex 
semata. Aksesibilitas merupakan persoalan yang lebih luas, menyangkut pada jalan menuju keseluruhan jaringan pelayanan dan kesempatan sebagai hal yang lumrah atau menjadi hal yang biasa bagi masyarakat umum.

\section{Transjakarta Cares}

Pemerintah provinsi DKI Jakarta terus membenahi kota agar lebih ramah untuk semua, tak terkecuali warga dengan disabilitas. Salah satu terobosan di sektor transportasi adalah kehadiran mobil Transjakarta Cares. Layanan yang diinisiasi oleh PT Transportasi Jakarta ini diresmikan oleh Gubernur DKI Jakarta Basuki Tjahaja Purnama pada bulan Otober 2016 di Balaikota.

Mobil khusus ini diawaki oleh 1 orang pramudi dan 2 orang petugas yang sudah dilatih khusus melayani difabel. Layanan ini mencakupi seluruh Jakarta dan beroperasi dari pukul 08.00 sampai dengan 17.00 WIB setiap hari. Pelanggan difabel dapat memesan mobil Transjakarta Cares dengan cara menghubungi call center 1500102 satu hari sebelumnya. Penjemputan akan dilakukan di lokasi asal pelanggan (rumah dan sebagainya) untuk diantar ke halte ramah difabel terdekat. Selanjutnya pelanggan dapat melanjutkan perjalanan dengan bus, dan setelah sampai di halte tujuan, akan diantar lagi dengan mobil Trans Cares lainnya hingga sampai lokasi tujuan.

Pemerintah Provinsi DKI Jakarta dan PT Transportasi Jakarta sudah memproyeksikan ada sekitar 75 halte yang dapat diubah menjadi halte ramah difabel dan saat ini sedang dalam proses pembenahan. Halte ramah difabel juga akan dilengkapi dengan toilet dan sebagai penanda bahwa halte tersebut ramah difable akan diberi cat warna hijau muda pada tiang ram jembatan penghubung dengan jembatan penyeberangan orang. Izin Mendirikan Bangunan adalah izin yang diberikan untuk kegiatan membangun. Izin dapat diterbitkan apabila rencana bangunan dinilai telah sesuai dengan ketentuan yang meliputi aspek planologis, aspek teknis, aspek kesehatan, aspek kenyamanan dan aspek lingkungan.

\section{METODE PENELITIAN}

Penelitian ini menggunakan jenis penelitian kualitatif. Penelitian dilakukan di

17 Available online at website: http://journal.uta45jakarta.ac.id/index.php/admpublik/iex 
wilayah Provinsi DKI Jakarta. Alasan penulis memilih tempat tersebut karena sebagai Ibu Kota Negara dan juga kota metropolitan, transportasi publik yang baik di Jakarta sangat diperlukan untuk menunjang mobilitas para warganya. Provinsi DKI Jakarta dituntut untuk memenuhi kebutuhan transportasi seluruh warganya tanpa terkecuali.. Sumber data dalam penelitian ini terbagi menjadi dua yakni data primer dan sekunder. Data primer didapatkan melalui wawancara dengan informan sedangkan data sekunder yakni berupa dokumen-dokumen yang mendukung kelengkapan data penelitian. Informan dalam penelitian ini adalah Kepala dan petugas Transjakarta Cares serta masyarakat penyandang disablitas. Teknik pengumpulan data dilakukan dengan cara wawancara, observasi dan dokumentasi sedangkan untuk analisis data dilakukan melalui pengumpulan data, reduksi data, penyajian data serta penarikan kesimpulan.

\section{Implementasi Layanan Publik Transjakarta Cares Dalam Meningkatkan} Aksesibilitas Penyandang Disabilitas Di Wilayah DKI Jakarta

\section{Sasaran dan Tujuan Dasar Kebijakan}

Kinerja implementasi kebijakan dapat diukur tingkat keberhasilannya dari ukuran dan tujuan kebijakan yang bersifat realistis dengan sosio-kultur yang ada di level pelaksana kebijakan, menurut Agustino (2006). Ketika ukuran dan sasaran kebijakan terlalu ideal, maka akansemakin sulit untuk direalisasikan. Untuk mengukur kinerja implementasi kebijakan tentunya menegaskan standar dan sasaran tertentu yang harus dicapai oleh para pelaksana kebijakan, kinerja kebijakan pada dasarnya merupakan penilaian atas tingkat ketercapaian standar dan sasaran tersebut.

Transjakarta Cares standar dan tujuanya sudah tertera pada visi dan misi dari Transjakarta Cares itu sendiri, yang secara garis besar pembentukannya bertujuan untuk mempermudah mobilitas masyarakat penyandang disabilitas. Tujuan dari adanya kebijakan layanan Transjakarta Cares ini adalah untuk memberikan kemudahan akses transportasi bagi para penyandang disabilitas serta membantu para pengguna untuk lebih mudah dalam menjalankan aktivitas sehari- hari dan sasaran yang dituju dari kebijakan ini adalah masyarakat penyandang kaum disabilitas. 
Berdasarkan hasil penelitian ini, dalam memberikan pelayanan Transjakarta Cares ini para petugas memahami dengan baik apa tujuan dan sasaran dari kebijakan layanan Transjakarta Cares ini. Hal ini berarti pemhaman akan sasaran dan tujuan kebijakan tidak akan menjadi halangan atau kendala dalam pengimplementasian layanan Transjakarta Cares dalam meningkatkan aksesibilitas penyandang disabilitas di Wilayah Provinsi DKI Jakarta.

\section{Sumber Daya}

Sumber daya merupakan salah satu hal yang memiliki peranan penting dalam implementasi suatu kebijakan.Sumber daya yang dimaksud disini berkaitan dengan segala sumber yang digunakan guna mendukung keberhasilan implementasi suatu kebijakan.Sumber daya tersebut mencakup sumber daya manusia dan fasilitas.Menurut Edward III dalam Nugroho (2014) untuk menilai memadai atau cukup tidaknya sumber daya yang dalam hal ini manusia dapat dilihat melalui kualitas dan kuantitas yang dimiliki.

Berdasarkan hasil penelitian dan wawancara yang telah disampaikan oleh informan penelitian, dapat dikatakan bahwa dengan sumber daya yang ada sudah cukup memadai dalam hal kuantitas serta kualitas sumber daya manusia.Petugas layanan memiliki kompetensi yang baik dalam melayani para pengguna Transjakarta Cares. Dalam hal jumlah fasilitas yang dimiliki, dari pertama kali diluncurkan kebijakan tersebut sampai saat ini armada yang dimiliki untuk melayani para penyandang disabilitas yakni sebanyak 40 unit mobil, jumlah ini dinilai belum cukup memadai karena tingginya antusias penyandang disabilitas untuk menggunakan layanan sedangkan unit yang tersedia tidak cukup banyak sehingga pelayanan yang dilakukan belum bisa dilakukan secara menyeluruh, walaupun begitu para petugas tetap berusaha memberikan pelayanan yang optimal bagi para pengguna yakni penyandang disabilitas.

\section{Karakteristik Organisasi}

Gitosudarmo (2001) menjelaskan bahwa karakteristik organisasi atau karakteristik situasi kerja yaitu bagaimana hubungan dengan rekan kerja dan kebiasaan organisasi. Ketiga faktor itu akan mempengaruhi motivasi dalam lingkup

19 Available online at website: http://journal.uta45jakarta.ac.id/index.php/admpublik/iex 
organisasi dan membagi karakteristik situasi kerja atau organisasi menjadi, Kebijakan dan Kultur Organisasi serta Lingkungan kerja. Dalam implementasi layanan Transjakarta Cares ini, pihak Transjakarta berkomunikasi baik dengan pihak komunitas penyandang disabilitas yakni Himpunan Wanita Disabilitas Indonesia (HWDI) sehingga Transjakarta seringkali mengikuti kegiatan-kegiatan yang dilakukan oleh organisasi atau komunitas penyandang disabilitas tersebut. Adapun kebiasaan yang dilakukan dalam organisasi yakni apel pagi degan tujuan untuk menerapkan disiplin waktu kepada para pegawai. Dalam kegiatan apel pagi, kepala Transjakarta Cares juga selalu memberikan semangat dan motivasi kerja untuk para petugasnya agar petugas selalu semangat dan disiplin dalam menjalankan tugasnya

\section{Sikap Para Pelaksana}

Howard dan Kendler (dalam Gerungan, 2000) mengemukakan batasan tentang sikap dimana dikatakan bahwa sikap merupakan kecenderungan individu untuk merespon dengan cara yang khusus terhadap stimulus yang ada dalam lingkungan sosial. Sikap merupakan suatu 3 kecenderungan untuk mendekat atau menghindar, positif atau negatif terhadap berbagai keadaan sosial, apakah itu institusi, pribadi, situasi, ide, konsep dan sebagainya. Dalam penelitian ini, konteks sikap yang dilihat adalah komitmen petugas atau pegawai (komitmen organisasi) dalam memberikan pelayanan.

Berdasarkan hasil penelitian dapat dikatakan bahwa bahwa para pelaksana atau implementor sangat mendukung adanya kebijakan pelayanan Transjakarta Cares ini karena dengan adanya Transjakarta Cares ini tentunya dapat membantu para kaum disabilitas untuk bisa lebih mudah mengakses transportasi umum. Para pelaksana berkomitmen untuk memberikan pelayanan yang terbaik bagi kaum disabilitas, selain itu kebijakan ini juga diharapkan mampu meningkatkan kepedulian masyarakat terhadap kaum disabilitas. Komitmen tersebut dibuktikan dengan menjalankan tugas yakni memberikan layanan TJ Cares kepada para penyandang disabilitas sesuai sesuai dengan peraturan yang telah ditetapkan serta tanpa lelah memberikan pelayanan yang optimal untuk penyandang disabilitas dan para pengguna juga menyatakan kepuasan akan pelayanan yang diberikan oleh para petugas layanan Transjakarta Cares.

20 Available online at website: http://journal.uta45jakarta.ac.id/index.php/admpublik/iex 


\section{Komunikasi}

Komunikasi adalah sebuah kegiatan mentransfer sebuah informasi baik secara lisan maupun tulisan. Namun, tidak semua orang mampu melakukan komunikasi dengan baik. Terkadang ada orang yang mampu menyampaikan semua informasi secara lisan tetapi tidak secara tulisan ataupun sebaliknya. Komunikasi efektif tejadi apabila pesan yang diberitahukan komunikator dapat diterima dengan baik atau sama oleh komunikan, sehingga tidak terjadi salah persepsi. Berdasarkan hasil penelitian, komunikasi yang terjadi dalam organisasi atau dalam hal ini Transjakarta Cares sudah cukup efektif. Bentuk komunikasi yang dilakukan ialah komunikasi secara lisan. Komunikasi dalam bentuk koordinasi secara lisan selalu dilakukan oleh kepala serta koordinator Transjakarta Cares setiap harinya melalui apel pagi dan briefing kepada petugas layanan Transjakarta Cares sebelum menjalankan tugasnya. Selain itu, komunikasi juga terjadi setiap satu minggu sekali dalam bentuk pertemuan rapat untuk menyampaikan laporan pencapaian tugas yang telah dilaksanakan.

\section{Kondisi Lingkungan}

Lingkungan kebijakan dapat dilihat melalui tiga aspek yakni Kondisi sosial ekonomi masyarakat dan tingkat kemajuan teknologi, dukungan publik, dan komitmen dan keterampilan implementor.Kondisi lingkungan yang digali dalam penelitian ini ialah dukungan publik terhadap kebijakan Transjakarta Cares ini. Menurut Cobb dalam shinta (1995) dukungan sosial adalah pemberian informasi baik secara verbal maupun non verbal, pemberian bantuan tingkah laku atau materi yang didapat dari hubungan sosial yang akrab atau hanya disimpulkan dari keberadaan mereka yang membuat individu merasa diperhatikan, bernilai dan dicintai, sehingga dapat menguntungkan bagi kesejahteraan individu yang menerima.

\section{Faktor Penghambat dan Pendukung Implementasi Layanan Publik Transjakarta Cares Dalam Meningkatkan Aksesibilitas Penyandang Disabilitas Di Wilayah Provinsi DKI Jakarta}

Dalam implementasi sebuah kebijakan, tentu ada hal-hal atau faktor-faktor yang mendukung implementasi agar dapat berjalan dengan baik. Sama halnya dengan implementasi layanan publik Transjakarta Cares. Dalam melaksanakan layanan ini di

$21 \quad$ Available online at website: http://journal.uta45jakarta.ac.id/index.php/admpublik/iex 
dukung oleh: koordinasi yang baik, komitmen petugas Transjakarta Cares, dan dukungan public.

Dalam melaksanakan tugasnya untuk memberikan layanan kepada kaum disabilitas para petugas layanan sebelumnya diberikan arahan terlebih dahulu oleh koordinator lapangan dimana arahan tersebut berisi tentang medan yang akan dituju, kondisi pengguna layanan. Sehingga petugas yang nantinya akan melayani pengguna jasa Transjakarta Cares sudah paham betul tentang kondisi dan tugasnya.

Petugas Transjakarta Cares berkomitmen untuk memberikan pelayanan yang optimal bagi para penyandang disabilitas sebagai pengguna jasa layanan Transjakarta Cares. Pelayanan yang diberikan tentu sesuai dengan prosedur yang ditetapkan oleh Transjakarta Cares. Pelayanan yang baik tentu akan memberikan kepuasan terhadap pengguna layanan.

Setiap kebijakan memerlukan dukungan dari berbagai pihak terutama pemerintah serta pengguna layanan sebagai sasaran kebijakan. Adanya Transjakarta Cares ini sangat didukung oleh pemerintah, pihak swasta yang dalam hal ini CSR dengan memberikan bantuan armada mobil untuk layanan serta para penyandang disabilitas sebagai pengguna layanan. Dengan adanya dukungan ini layanan Transjakarta Cares dapat berjalan baik dan mencapai tujuannya untuk memudahkan akses transportasi bagi para penyandang disabilitas.

Pelaksanaan layanan Transjakarta Cares ini belum bisa dilakukan secara menyeluruh dan merata kepada kaum disabilitas mengingat armada yang tersedia untuk pelayanan masih kurang memadai.Sampai saat ini armada yang dimiliki hanya 40 unit, sedangkan antusias para kaum disabilitas untuk menggunakan layanan Transjakarta Cares ini sangat tinggi setiap harinya.

\section{SIMPULAN}

Berdasarkan pembahasan yang sudah diuraikan pada bab sebelumnya dapat ditarik kesimpulan bahwa implementasi layanan Publik Transjakarta Care dalam meningkatkan Aksesibilitas Penyandang Disabilitas di Wilayah Provinsi DKI Jakarta telah dilaksanakan. Tujuan, sasaran dan layanan ini untuk memudahkan para 
penyandang disabilitas dalam mengaskes layanan transportasi umum. Pelaksanaan layanan Transjakarta Cares memiliki karakteristik organisasi bahwa Transjakarta Care selalu dilibatkan dalam kegiatan organisasi penyandang disabilitas, dan para petugas berkomitmen untuk memberikan pelayanan yang optimal sesuai dengan prosedur serta kebutuhan para pengguna layanan. Selain itu pelaksanaan layanan ini didukung oleh sumberdaya manusia yang terampil namun demikian masih belum ada dukungan serta fasilitas yang memadai. Untuk memudahkan para petugas dalam melaksanakan pekerjaan maka kepala dan koordinator Transjakarta Cares memberikan arahan setiap hari kepada para petugas sebelum melaksanakan tugasnya. Layanan Transjakarta Care ini juga didukung oleh berbagai pihak baik pemerintah, swasta maupun penyandang disabilitas sebagai pengguna layanan.

Sebagai penyedia jasa transportasi public bagi warga DKI Jakarta khususnya penyandang disabilitas, masih perlu dilakukan kerjasama dengan pihak swasta lainnya untuk menambah armada mobil sertas memberikan fasilitas-fasilitas kesehatan guna lebih meningkatkan pelayanan yang lebih optimal dan menyeluruh kepada kaum disabilitas. Hal tersebut dimaksudkan agar tercipta suasana yang nyaman, sehat, dan aman bagi para Penyandang Disabilitas.

\section{DAFTAR PUSTAKA}

\section{Sumber Buku:}

AG, S. (2011). Analisis Kebijakan Publik (Konsep, Teori, Aplikasi). Yogyakarta: Pustaka Pelajar. Fakih, D. M. (2004). Pokok-Pokok Pemikiran Dr. Mansoer Fakih: Refleksi Kawan Seperjuangan. Yogyakarta: Resist Book.

Gito Sudarmo, Indriyo. (2001). Manajemen strategi.Yogyakarta: BPFE YOGYAKARTA.) Gerungan, W.A. (2000). Psikologi Sosial. Bandung: Refika Aditama

Herdiansyah, H. (2010). Metodologi Penelitian Kuantitatif. Jakarta: Salemba.

Jakarta, L. B. (2015). Mereka yang Dihambat . Laporan Pemeringkatan Indeks Aksesibilitas Fasilitas Publik bagi .

Kurniawan, H. (2017). Perancangan Aksesibilitas untuk Fasilitas Publik. Yogyakarta:

23 Available online at website: http://journal.uta45jakarta.ac.id/index.php/admpublik/iex Copyright $\odot$ 2020|IJPA|E-ISSN:2460-0369 
Gajah Mada Univercity Press.

Marzuki. (2000). Metodelogi Riset. Yogyakarta: Prasetia

Widia Pratama. Miro, F. (2012). Pengantar Sistem Transportasi. Jakarta: Erlangga.

Moleong, L. J. (2006). Metodologi Penelitian Kualitatif. Bandung: PT. Remaja Rosdakarya. Moleong, L. (2011). Metodologi Penelitian Kualitatif Edisi Revisi. Bandung: PT. Remaja Rosdakarya.

Nugroho, D. R. (2014). Publik Policy. Jakarta: PT Elex Media Komputindo.

Prastowo, A. (2011). Metode Penelitian Kualitatif dalam Perspektif Rancangan. Jogjakarta: Ar- Ruzz Media.

Rahardjo Adisasmita dan Sakti Adji Sasmita.2011.Manajemen Transportasi Darat, Graha Ilmu.Yogyakarta

Ro'fah. (2010). Membangun Kampus Inklusif. Yogyakarta : PSLD UIN Suanan Kalijaga. Sugiyono. (2011). Metode Penelitian Kuantitatif, Kualitatif dan R\&D. Bandung: Alfabeta. Sunggono, B. (2004). Metode Penelitian Sosial Dan Hukum. Jakarta: Granit.

Susantoro, Bambang \& Danang Parikesit, "1 -2-3 Langkah: Langkah Kecil yang Kita Lakukan Menuju Transportasi yang Berkelanjutan,” Majalah Transportasi Indonesia, Vol. 1, Jakarta, 2004:89-95.

Shinta, E. (1995). Perilaku Coping dan Dukungan Sosial Pada Pemuda Penganggur Studi Deskriptif terhadap Pemuda Penganggur di Perkotaan.Jurnal Psikologi Indonesia.Nomor Halaman 1-7.

Wahab, S. A. (2008). Analisis Kebijakan Dari Formulasi ke Implementasi Kebijakan Negara. Jakarta: PT Bumi Aksara.

Winarno, B. (2008). Kebijakan Publik: Teori dan Proses . Jakarta: PT Buku Kita.

\section{Sumber Jurnal:}

Adele Crudden, Karla Antonelli, dan Jamie O’Mally. 2017. A Customized 
Transportation intervention for persons with visual impairments. U.S.A

Al Rasyid, Rio Bagus Firmansyah. 2015. Kualitas Pelayanan Transportasi Publik (

Studi Deskriptif tantang Kualitas Pelayanan Jasa Angkutan Umum Damri Unit Angkutan Bus Khusus Gresik-Bandara Juanda). Universitas Muhamadiyah Yogyakarta.

Aminah, Siti. 2007. Transportasi Publik dan Aksesibilitas Masyarakat Perkotaan, Jurusan Ilmu Politik FISIP, Universitas Airlangga.

Kirsty McCaskill and Anne Goulding. 2004.English Publik library service and the disability discrimination act. Ingris

Kusnawan, I Gede dan IAGusti NgurahAWairocana, Ni GustiAAyu DyahASatyawati, 2017. Kewenangan Pemerintah Provinsi Bali Terhadap Perlindungan Disabilitas, Jurnal Kertha Negara Vol. 04, No.05 Juli 2016 Fakultas Hukum Universitas Udayana.

Rafael Lind Qvist dan Jorgen Lundalv.2012. Participation in Work life and access to publik transport - lifed experiences of people with Disabilities insueden. Swedia.

Sulastri, Andi. 2014. Tinjauan Hukum Terhadap Penyediaan Aksesibilitas Bagi Penyadang Disabilitas di Kota Makassar. Universitas Hasanudin Makasar.

\section{Dokumen Dokumen :}

Peraturan Menteri Pekerjaan Umum Nomor 30 Tahun 2006 tentang Pedoman Teknis Fasilitas dan Aksesibilitas pada Bangunan Gedung dan Lingkungan

Peraturan Menteri Perhubungan Nomor 71 tahun 1999 tentang Standar Aksesibilitas Prasarana Angkutan Umum

Undang-Undang Nomor 8 Tahun 2016 tentang Penyandang

Disabilitas Undang-Undang Nomor 4 tahun 1997 tentang

Penyandang Cacat Undang-Undang Nomor 28 Tahun 2002

\section{Sumber Web:}

(2010). Retrieved April 01, 2018, from Badan Pusat Statistik:

25 Available online at website: http://journal.uta45jakarta.ac.id/index.php/admpublik/iex 
http://sp2010.bps.go.id/index.ph p/site/topik?kid=9\&kategori=KesejahteraanSosial

(2015). Retrieved Maret 30, 2018, from Jakarta Open Data:

http://data.jakarta.go.id/dataset/data jumlah-penduduk-penyandang-disabilitasper-wilayah

(2016). Retrieved April 01, 2018, from Kementerian Sosial Republik Indonesia:

https://www.kemsos.go.id/modules.php?name=News\&file=article\&sid=1013

Disabilities dan Rehabilitation. (2016). Retrieved April Minggu, 2018, from World Health Organization (WHO): http://www.who.int/disabilities/data/en/ 